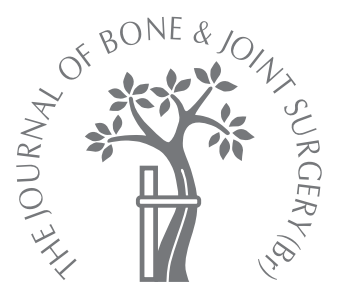

P. Culpan,

V. Le Strat, P. Piriou, T. Judet

From Hôpital Raymond Poincare, Garches, France
P. Culpan, FRCS(Trauma \& Orth), Orthopaedic Fellow - V. Le Strat, MD, Orthopaedic Intern

P. Piriou, MD, PhD, Professor T. Judet, MD, Professor Department of Orthopaedic Surgery and Traumatology Hôpital Raymond Poincare, 92380 Garches, Paris, France.

Correspondence should be sent to Mr P. Culpan; e-mail: paulculpan@doctors.net.uk

(C2007 British Editorial Society of Bone and Joint Surgery doi:10.1302/0301-620X.89B9. $19108 \$ 2.00$

$J$ Bone Joint Surg $[\mathrm{Br}]$ 2007;89-B:1178-83.
Received 8 January 2007 Accepted after revision 15 May 2007

\section{Arthrodesis after failed total ankle replacement}

\begin{abstract}
We present a series of 16 patients treated between 1993 and 2006 who had a failed total ankle replacement converted to an arthrodesis using bone grafting with internal fixation. We used tricortical autograft from the iliac crest to preserve the height of the ankle, the malleoli and the subtalar joint. A successful arthrodesis was achieved at a mean of three months (1.5 to 4.5 ) in all patients except one, with rheumatoid arthritis and severe bone loss, who developed a nonunion and required further fixation with an intramedullary nail at one year after surgery, before obtaining satisfactory fusion. The post-operative American Orthopaedic Foot and Ankle Society score improved to a mean of 70 (41 to 87) with good patient satisfaction. From this series and an extensive review of the literature we have found that rates of fusion after failed total ankle replacement in patients with degenerative arthritis are high. We recommend our method of arthrodesis in this group of patients. A higher rate of nonunion is associated with rheumatoid arthritis which should be treated differently.
\end{abstract}

Ankle replacement has had a resurgence of interest with improved mid-term results now being reported with the newer designs compared with poor results from earlier prostheses. $^{1-5}$

Although the survivorship of the second generation of ankle replacements has improved, it still does not match that of total hip and knee replacement. A higher level of reoperation after total ankle replacement (TAR) has been reported. ${ }^{6}$ Surgery after a failed TAR presents considerable challenges for the surgeon who will often be faced with extensive bone loss, poor soft tissues and hindfoot pathology. Revision arthroplasty has not been shown to be a reliable option leaving arthrodesis as the preferred management.

We report a series of 16 patients who had a failed TAR converted to an ankle arthrodesis using tricortical autograft from the iliac crest to preserve height, while maintaining the malleoli and subtalar joint. Our aim was to evaluate the place of this technique and to assess the outcome.

\section{Patients and Methods}

Between 1993 and 2006, 16 patients with a failed TAR underwent arthrodesis by the senior author (TJ). There were 11 women and five men with a mean age of 54 years (24 to 78). The initial diagnosis was either primary or post-traumatic osteoarthritis (OA) in 13 patients, rheumatoid arthritis (RA) in two and pigmented villonodular synovitis in one patient. The implants used included eight Salto (Tornier Implants, Grenoble, France) prostheses, three Buechel Pappas (Endotech Inc, South Orange, New Jersey) prostheses, two STAR (Waldemar Link, Hamburg, Germany), one New Jersey (DePuy, Warsaw, Indiana), one Ramses (Ortho, Heimsbrunn, France) and one custom-made implant (Table I). The mean time from TAR to arthrodesis was 41 months (10 to 144). In most cases, the mode of failure was aseptic loosening and migration of components (Fig. 1). In two patients, initial osseous integration of the prosthesis had not been achieved leading to early failure. In addition, one arthrodesis was undertaken for persistent pain in the absence of an identifiable cause and one for failure resulting from infection.

The arthrodesis was the primary revision procedure in the 15 patients with aseptic failure of their TAR. For the patient with infection the arthrodesis was staged with removal of components and debridement of the joint and external fixation before bone grafting and internal fixation as a second procedure once the infection has been eliminated.

Operative technique. The principles on which the procedure is based are preservation of the height of the ankle by replacing bone loss with 


\begin{tabular}{|c|c|c|c|c|c|c|c|c|c|c|}
\hline \multirow[b]{3}{*}{ Case } & \multirow[b]{3}{*}{$\begin{array}{l}\text { Age } \\
\text { (yrs) }\end{array}$} & \multirow[b]{3}{*}{ Diagnosis $^{*}$} & \multirow[b]{3}{*}{ Implant } & \multirow[b]{3}{*}{$\begin{array}{l}\text { Reason for } \\
\text { failure }\end{array}$} & \multirow{3}{*}{$\begin{array}{l}\text { Time to } \\
\text { failure } \\
\text { (yrs) }\end{array}$} & \multirow[b]{3}{*}{ Arthrodesis } & \multirow[b]{3}{*}{$\begin{array}{l}\text { Time to union } \\
\text { (mths) }\end{array}$} & \multicolumn{3}{|l|}{ AOFAS $^{\dagger}$ score } \\
\hline & & & & & & & & \multirow[b]{2}{*}{ Pre-operative } & \multicolumn{2}{|c|}{ Post-operative } \\
\hline & & & & & & & & & Pain & Total \\
\hline 1 & 50 & PTOA & New Jersey & $\begin{array}{l}\text { Component } \\
\text { malalignment }\end{array}$ & 2.0 & Tricortical graft & 3.0 & 16 & 40 & 78 \\
\hline 2 & 56 & PTOA & Buechel Pappas & $\begin{array}{l}\text { Aseptic } \\
\text { loosening }\end{array}$ & 3.0 & Tricortical graft & 3.0 & 37 & 20 & 55 \\
\hline 3 & 64 & PTOA & Buechel Pappas & $\begin{array}{l}\text { Aseptic } \\
\text { loosening }\end{array}$ & 12.0 & Tricortical graft & 3.0 & 40 & 30 & 60 \\
\hline 4 & 51 & PTOA & Mendolia & $\begin{array}{l}\text { Aseptic } \\
\text { loosening }\end{array}$ & 2.5 & $\begin{array}{l}\text { Tricortical graft } \\
\text { 1st stage - external fixator }\end{array}$ & 3.0 & 24 & 40 & 86 \\
\hline 5 & 71 & PTOA & Buechel Pappas & Infection & 2.0 & 2nd stage - tricortical graft & 3.5 & & 40 & 87 \\
\hline 6 & 39 & PTOA & Salto & $\begin{array}{l}\text { Aseptic } \\
\text { loosening }\end{array}$ & 3.0 & Tricortical graft & 2.5 & 12 & 40 & 82 \\
\hline 7 & 55 & PVNS & $\mathrm{STAR}^{\ddagger}$ & $\begin{array}{l}\text { Aseptic } \\
\text { loosening }\end{array}$ & 4.0 & Tricortical graft & 3.0 & 26 & 30 & 71 \\
\hline 8 & 60 & OA & Salto & Persistent pain & 1.0 & Tricortical graft & 4.0 & 16 & 20 & 41 \\
\hline 9 & 24 & RA - juv & Salto & $\begin{array}{l}\text { Migration } \\
\text { into talar } \\
\text { dome }\end{array}$ & 1.5 & $\begin{array}{l}\text { Tricortical graft revised to } \\
\text { intramedullary nail at one } \\
\text { year }\end{array}$ & Nonunion & 38 & 40 & 76 \\
\hline 10 & 50 & RA & Salto & $\begin{array}{l}\text { Aseptic } \\
\text { loosening }\end{array}$ & 5.0 & Tricortical graft/plate & 2.0 & 46 & 40 & 73 \\
\hline 11 & 60 & OA & Salto & $\begin{array}{l}\text { Migration/ } \\
\text { granuloma }\end{array}$ & 4.0 & Tricortical graft & 4.5 & 56 & 30 & 75 \\
\hline 12 & 45 & PTOA & Salto & $\begin{array}{l}\text { Migration/ } \\
\text { granuloma/ } \\
\text { subluxation }\end{array}$ & 2.0 & Tricortical graft & 3.0 & & 40 & 75 \\
\hline 13 & 50 & PTOA & Custom & $\begin{array}{l}\text { Osteolysis } \\
\text { subluxation/ } \\
\text { wear }\end{array}$ & 1.0 & Tricortical graft & 3.0 & 38 & 40 & 64 \\
\hline 14 & 78 & PTOA & Salto & $\begin{array}{l}\text { Spacer } \\
\text { Failure }\end{array}$ & 1.0 & Tricortical graft & 3.5 & & 40 & 67 \\
\hline 15 & 68 & PTOA & STAR & $\begin{array}{l}\text { Osseous } \\
\text { integration }\end{array}$ & 1.0 & Tricortical graft/plate & 3.5 & & 40 & 74 \\
\hline 16 & 52 & PTOA & Salto & $\begin{array}{l}\text { Migration/ } \\
\text { granuloma }\end{array}$ & 6.0 & Tricortical graft/plate & 3.0 & 28 & 20 & 57 \\
\hline
\end{tabular}

* PTOA, post-traumatic osteoarthritis; PVNS, pigmented villonodular synovitis; OA osteoarthritis; RA, rheumatoid arthritis

${ }^{\dagger}$ AOFAS, American Orthopaedic Foot and Ankle Society

${ }^{\ddagger}$ STAR, Scandinavian total ankle replacement

corticocancellous autograft while maintaining the malleoli to improve rotational stability with control of normal tracking of the tendons and preservation of the subtalar joint. The technique is a modification of that previously described by Groth and Fitch. ${ }^{7}$ The use of corticocancellous graft was first described by Chiunard and Peterson ${ }^{8}$ although Campbell, Rinehart and Kalenak ${ }^{9}$ modified the orientation of the graft from horizontal to vertical which is our preferred technique.

The ankle is exposed through the previous anterior incision and the implants removed with care to minimise further bone loss. The joint is debrided of all nonviable bone and scar tissue. Corticocancellous bone graft is harvested from the iliac crest and fashioned to obtain optimal filling of the joint space with two or three corticocancellous grafts orientated vertically. The height of the graft is tailored to fit the cavity. The foot is positioned with the ankle in neutral flexion or a few degrees of dorsiflexion, valgus angulation of the hindfoot $0^{\circ}$ to $5^{\circ}$ and external rotation of $5^{\circ}$ to $10^{\circ}$ to allow greatest compensatory movement of the foot and less strain on the knee. ${ }^{10}$ The contralateral side is used as a reference. The strut grafts are impacted into position, providing initial primary stability from the vertically orientated cortical bone and the cancellous bone gives the stimulus for osteogenesis. Screw fixation with $4.5 \mathrm{~mm}$ cortical screws is performed without breaching the subtalar joint (Fig. 2). From the anterior cortex of the tibia to the body of the talus two crossing screws are inserted in a lagged manner, the lateral screw being generally longer. One lag screw is inserted percutaneously from the fibula to the tibia and another from the lateral malleolus to the talus for additional stability. Intra-operative radiographs are taken to ensure that the subtalar joint is preserved.

When there is concern that optimal fixation has not been achieved a bridging plate is applied with two or three bicortical screws in the tibia, and two in the neck/ head of the talus (Fig. 3).

Post-operative management. The patients were immobilised, non-weight-bearing in a below-knee cast for two months and then allowed to weight-bear in a cast for a 


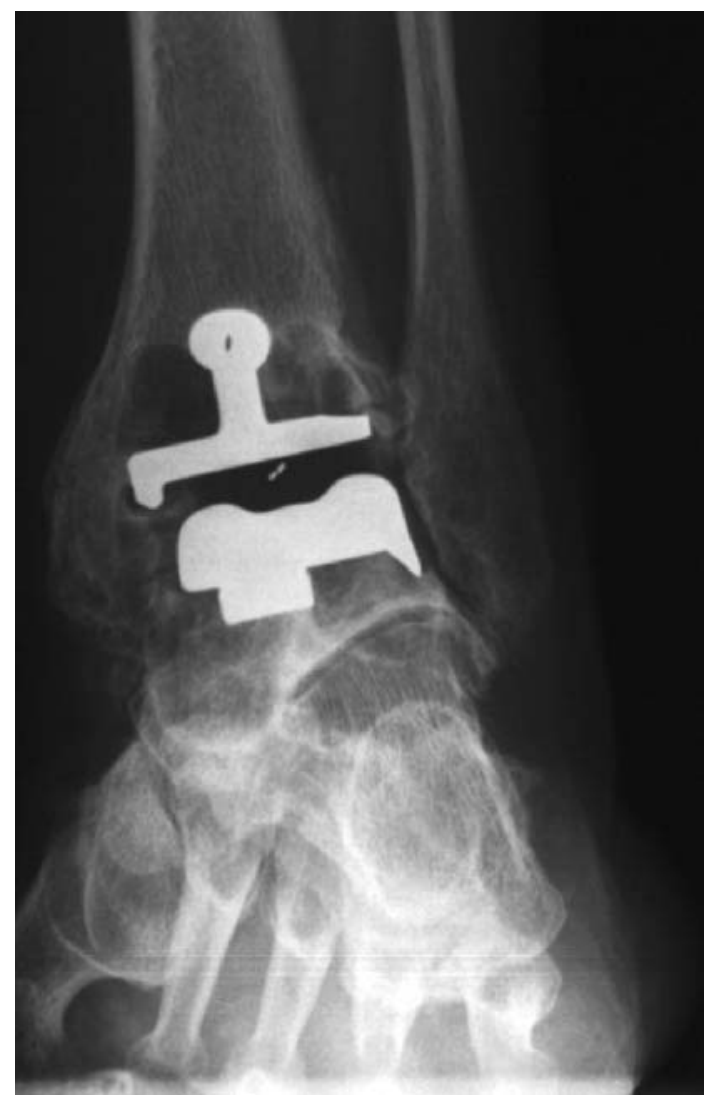

Fig. 1a

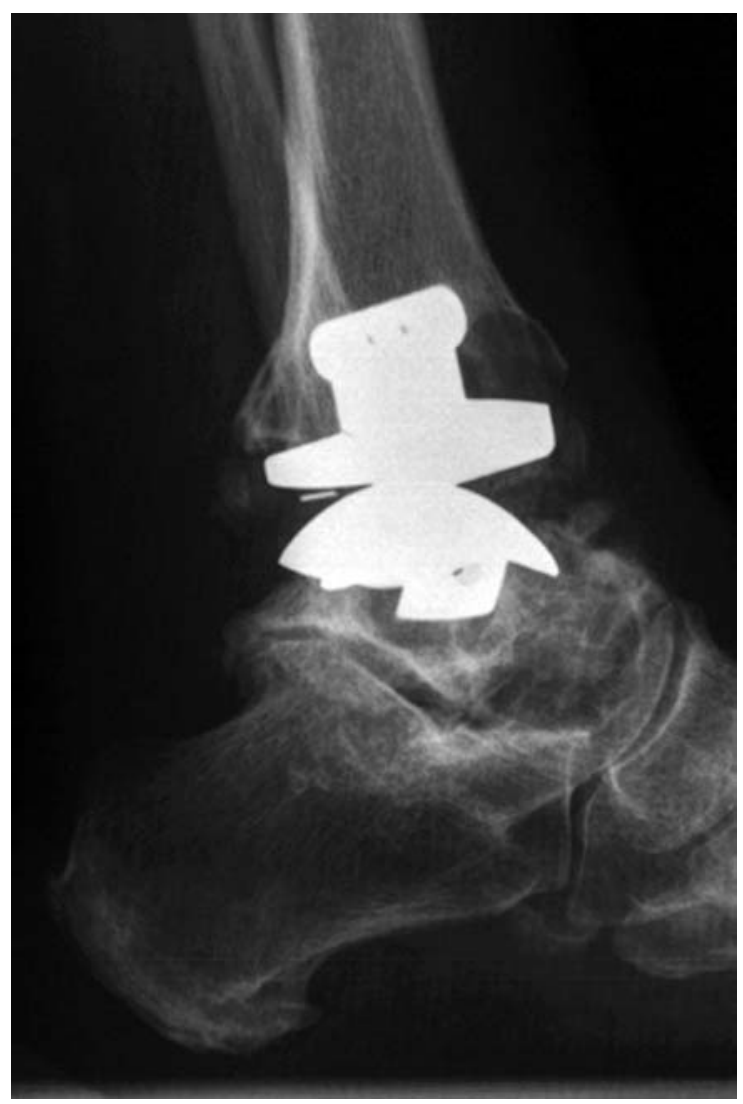

Fig. 1b

a) Anteroposterior and b) lateral radiographs showing a failed total ankle replacement.

further month. Anteroposterior (AP) and lateral radiographs were taken at each clinical review and if doubt continued regarding union CT was performed at three months.

All patients were reviewed post-operatively and a retrospective review of the medical notes and radiographs undertaken. The mean follow-up was three years and eight months (six months to 13 years) after arthrodesis. Radiological evidence of union was indicated by the presence of bridging trabeculae at the level of the arthrodesis. Clinical assessment of union was determined by the absence of movement and pain on stressing the arthrodesis and movement at the subtalar and midtarsal joints was assessed. The American Orthopaedic Foot and Ankle Society (AOFAS) ${ }^{11}$ hindfoot scores were recorded at follow-up. This system provides an overall outcome score out of 100 , of which a possible 50 points can be scored for function, 40 for pain and 10 for alignment. Pre-operative scores were recorded in 12 of 16 patients, and post-operative scores in all 16 . In addition, all patients were asked to rate their satisfaction with the outcome from excellent, satisfactory, unchanged and unhappy.

\section{Results}

All 16 patients had a successful arthrodesis both clinically and radiologically (Table I). The mean time from arthrodesis to fusion was three months (1.5 to 4.5). The mean AOFAS score pre-operatively was 31 (12 to 56); and at the most recent review was 70 (41 to 87 ). Subjectively, six patients rated their outcome as excellent and ten as satisfactory. The subtalar and midtarsal movement was generally maintained at the level found before arthrodesis. In the patients with RA the subtalar joints were already severely compromised by the arthropathy. In one patient, the subtalar joint had been fused before the original replacement and in the other it was fixed at the same time as the ankle arthrodesis.

Complications. No patient had wound breakdown, haematoma or infection. One patient with RA (case 9) developed nonunion. She had considerable bone loss at the talus and the initial corticocancellous grafting failed to unite. This was revised 12 months after the arthrodesis with the use of an intramedullary nail and successful fusion was then obtained.

\section{Discussion}

Ankle arthrodesis after a failed TAR has been recognised as a particularly difficult procedure with high rates of compli- 


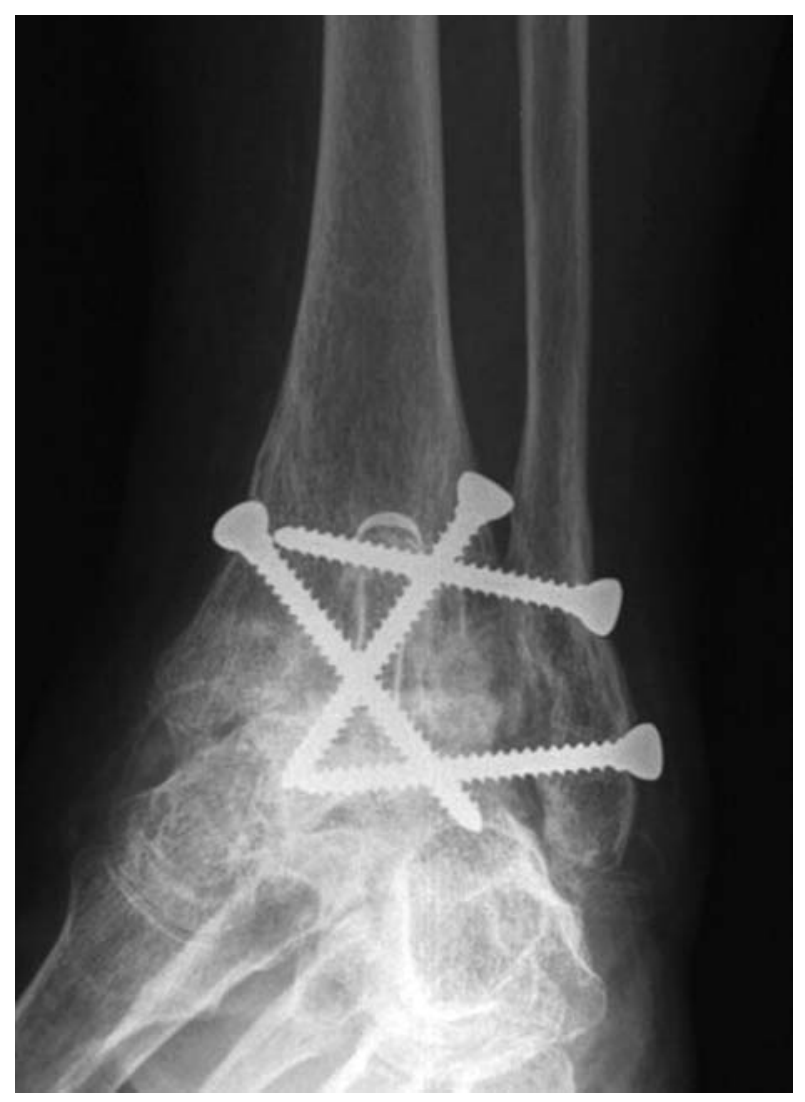

Fig. 2a

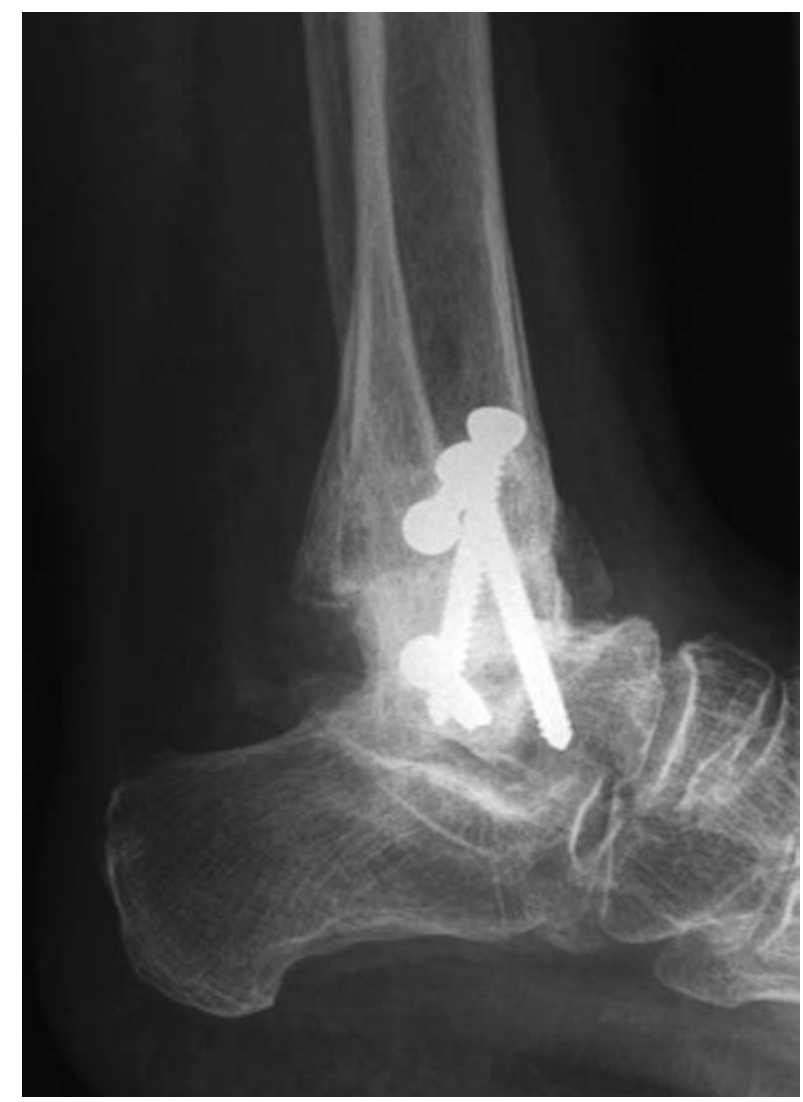

Fig. $2 b$

a) Anteroposterior and b) lateral radiographs showing arthrodesis of the ankle with structural graft and screw fixation.

cation, such as nonunion, and often results in considerable shortening. The management of failed TARs has been the subject of several studies advocating different methods of fixation. These are summarised in Table II. ${ }^{7,12-20}$

Our results compare favourably with other series. Successful union was achieved in all our patients except one who developed a nonunion. The mean time to fusion was three months.

In all of our patients in whom the AOFAS score was recorded before arthrodesis, a considerable improvement was achieved. Direct comparison with other series is difficult since not all have included a post-operative score, some have used a different scoring system, and some series contain more patients with RA. However, the mean AOFAS score achieved in our series is better than that recorded by others, ${ }^{12,13,16}$ which we believe, in part, is attributable to the principles of our technique and is approaching reported outcome scores following primary ankle arthrodesis. ${ }^{21} \mathrm{We}$ acknowledge that the most popular hindfoot scoring system, the AOFAS score, has not been validated and therefore caution should be used when comparing studies. ${ }^{22}$

We feel that our technique of protecting the subtalar joint by not including it in the fusion whenever possible and ensuring that function is not impaired by malaligning the hind foot in varus is fundamental to obtaining a good result. The tricortical graft with internal fixation also allows height to be preserved and is beneficial to the function of the tendons ${ }^{23}$ and to the gait since the fused ankle limits the ability of the foot to compensate for a leg-length discrepancy. The malleoli are preserved which benefits rotational alignment ${ }^{13}$ and tendon function.

It is of note that the mean age of the patients in our series at the time of the arthrodesis was only 54 years and that this group had experienced failure of their TAR at a mean of only 41 months. Whether these early failures are representative of the steep learning curve associated with TAR or of a higher risk of failure in the younger population as identified by Spirt et al, ${ }^{6}$ is difficult to determine. The two largest studies published in the literature report an identical mean time to arthrodesis as that in our series. ${ }^{15,20}$

Our review of the literature of ankle arthrodesis after failed TAR showed that external fixation in conjunction with autograft was the predominant method in three of the largest series. ${ }^{15,17,20}$ However, the corticocancellous graft was rarely placed with vertical orientation to restore the height of the ankle reliably. Although in some cases it was 


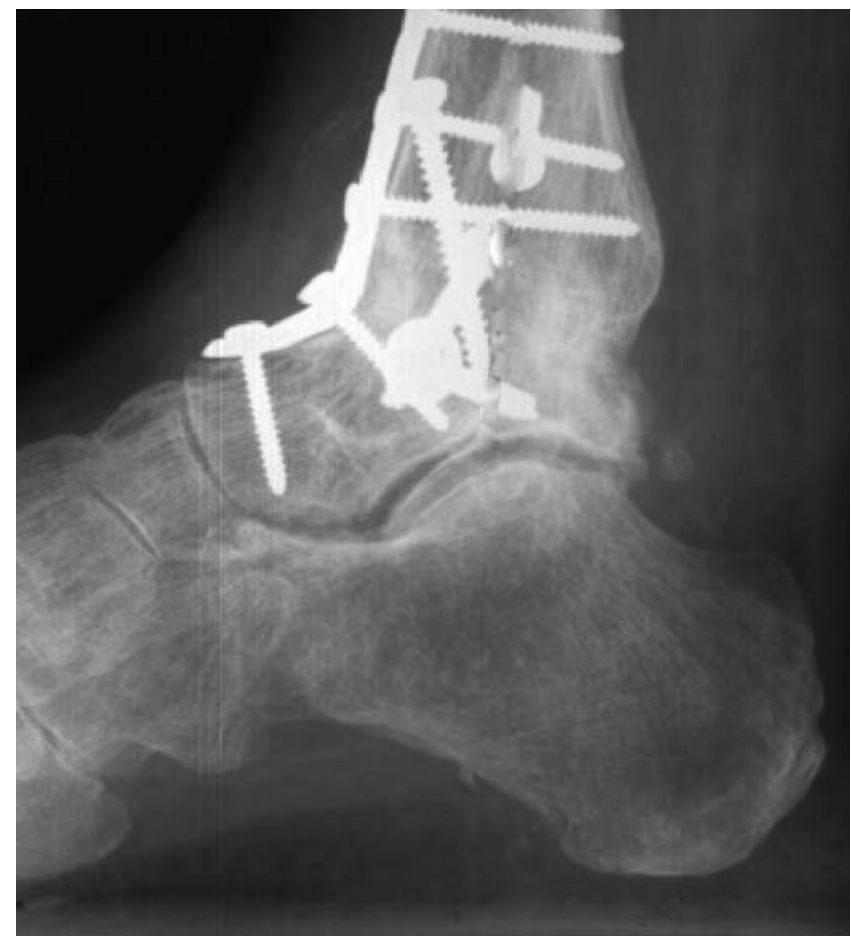

Fig. 3

Lateral radiograph showing arthrodesis with additional plate fixation.

possible to spare the subtalar joint this was generally not the case and external fixation was usually followed by immobilisation in a cast often for lengthy periods. In addition, external fixation has the drawback of the possibility of pin-track infection and requires greater co-operation from the patient.

The use of intramedullary nailing to achieve an arthrodesis has been reported in three recent studies. ${ }^{13,14,16}$ Bone graft was usually used although not as a structural graft. The major disadvantage of this method is that the subtalar joint is sacrificed in the hindfoot fusion and it is likely that some degree of shortening will result, despite the use of locking screws. This technique is very useful for the salvage of a nonunion or in cases in which only a minimal amount of the talus remains. This situation occurs more commonly in patients with RA in which the subtalar joint is often already severely compromised.

Those studies which used internal fixation as the method of fixation varied considerably both in the technique and results with none adhering to our principles. In the series reported by Hopgood et $\mathrm{al}^{13}$ the tibia and talus were always brought into contact with autograft, or more often synthetic substitute was used to fill cavities. Therefore shortening was inevitable. In the series by Gabrion et $\mathrm{al}^{12}$ a tricortical graft similar to that used by us was employed to restore length but less emphasis was placed on the preser- vation of the subtalar joint which was often included in the fusion. This may explain the lower AOFAS scores.

The severity of bone loss and the quality of bone remaining are likely to have an important influence on obtaining a satisfactory arthrodesis. The series of Hopgood et al ${ }^{13}$ provides an interesting overview. In this study there were eight patients all with OA who underwent tibiotalar arthrodesis with compression screws and achieved satisfactory union. In five patients with more extensive bone loss a tibiotalocalcaneal arthrodesis with compression screws was performed, but the four patients with RA all developed nonunion. In all series reporting higher rates of fusion, the case load contained few if any patients with RA. ${ }^{7,14,17,18}$ In those series with a higher number of patients with $\mathrm{RA}^{13,15,16,20}$ the fusion rates were lower (Table II). In the series of Hopgood et $\mathrm{al}^{13}$ greater success was obtained by the use of intramedullary nailing to achieve fusion in patients with RA, a finding in agreement with the recommendations made by Anderson et $\mathrm{al}^{16}$ following the series from Sweden which contained the largest series of patients with RA. ${ }^{15}$ It was concluded that the use of the intramedullary nail in this group was preferred to external fixation since the problems of pin-track infection were avoided, rehabilitation was faster and the surgery less technically demanding. Internal fixation with screws was not advised in these patients.

It would appear that a distinction should be made between patients with bone of poor quality and extensive bone loss, as is often the case with rheumatoid patients, and those with a non-inflammatory arthropathy and better bone quality.

In our one case of arthrodesis for failure from infection in an ankle replacement, we used an external fixator to maintain length as part of a staged procedure to eradicate the infection before bone grafting. External fixation has been successfully used in several series of ankle arthrodesis performed for infection ${ }^{14,15,20}$ and is ideally suited to the variety of procedures which may be required.

In our study, similar to earlier reports, ${ }^{13,14,17,20}$ we were able to achieve a successful arthrodesis, with a single surgical procedure and minimal fixation in all our patients whose original diagnosis had been degenerative disease. A tibiotalar calcaneal fusion results in a stiff foot which is unable to adapt to uneven ground, loses shock absorption and has reduced propulsion. ${ }^{24}$ With the encouraging results achieved in our series the use of an intramedullary nail and the sacrifice of the subtalar joint or the use of external fixation which generally must cross the subtalar joint, would seem to be unnecessary.

From our series and a review of the literature, it would appear that a successful fusion and a good clinical outcome can be expected in patients with degenerative arthritis in whom the bone quality and bone stock are generally better preserved. In such patients, we advocate the principles of autologous tricortical graft fusion with internal fixation which preserves the height of the ankle, the malleoli and the subtalar joint. 
Table II. Details of other studies

\begin{tabular}{|c|c|c|c|c|c|c|}
\hline Author/s & Fixation method & Number of cases & Number with RA* & $\begin{array}{l}\text { Total number } \\
\text { united }(\%)\end{array}$ & $\begin{array}{l}\text { Total number with } \\
\text { united RA (\%) }\end{array}$ & $\begin{array}{l}\text { Post-operative } \\
\text { AOFAS }^{\dagger} \text { score }\end{array}$ \\
\hline Stauffer $^{17}$ & External fixation/autograft & 17 & 0 & $17(100)$ & & \\
\hline Groth and Fitch ${ }^{7}$ & Autologous graft only & 11 & 0 & $11(100)$ & & \\
\hline $\begin{array}{l}\text { Kitaoka and } \\
\text { Romness }\end{array}$ & External fixation/autograft & 38 & 10 & $33(87)$ & & \\
\hline Kile et $\mathrm{al}^{18}$ & Intramedullary nail & 2 & & & & \\
\hline \multirow[t]{2}{*}{ Makwana et $\mathrm{al}^{19}$} & External fixation & 3 & 3 & $1(33)$ & $1(33)$ & \\
\hline & Intramedullary nail & 2 & 2 & $2(100)$ & & \\
\hline Carlsson et $\mathrm{al}^{15}$ & External fixation/autograft & 21 & 16 & $17(81)$ & $12(75)$ & \\
\hline Gabrion et al ${ }^{12}$ & Tricortical graft/plate & 8 & 2 & $7(87)$ & $1(50)$ & 54 \\
\hline Anderson et $\mathrm{al}^{16}$ & Intramedullary nail & 16 & 16 & $13(81)$ & $13(81)$ & 56 \\
\hline \multirow[t]{2}{*}{ Kontis et $\mathrm{al}^{14}$} & Intramedullary nail & 9 & 2 & $9(100)$ & $2(100)$ & \\
\hline & External fixation & 1 & & $1(100)$ & & \\
\hline \multirow[t]{3}{*}{ Hopgood et al ${ }^{13}$} & Compression screws, tibiotalar & 8 & 0 & $8(100)$ & & \\
\hline & $\begin{array}{l}\text { Compression screws, tibiotalocalca- } \\
\text { neal }\end{array}$ & 5 & 4 & $1(20)$ & $0(0)$ & 61 \\
\hline & Intramedullary nail & 10 & 7 & $8(80)$ & $6(86)$ & \\
\hline
\end{tabular}

* RA, rheumatoid arthritis

† AOFAS, American Orthopaedic Foot and Ankle Society

\section{Supplementary Material}

$\because$ A further opinion by Mr P. Wood is available with e the electronic version of this article on our website at www.jbjs.org.uk

The author or one or more of the authors have received or will receive benefits for personal or professional use from a commercial party related directly or indirectly to the subject of this article.

\section{References}

1. Lord G, Marotte TH. Total ankle prosthesis: technic and 1st results: a propos of 12 cases. Rev Chir Orthop Reparatrice Appar Mot 1973;59:139-51 (in French).

2. Bonnin M, Judet T, Colombier JA, et al. Midterm results of the Salto total ankle prosthesis. Clin Orthop 2004;424:6-18.

3. Anderson T, Montgomery F, Carlsson A. Uncemented STAR total ankle prostheses: three to eight year follow up of 51 consecutive ankles. J Bone Joint Surg [Am] 2003:85-A:1321-9.

4. Wood PLR, Deakin S. Total ankle replacement: the results in 200 ankles. J Bone Joint Surg [Br] 2003;85-B:334-41.

5. Bolton-Maggs BG, Sudlow RA, Freeman MAR. Total ankle arthroplasty: a longterm review of the London Hospital experience. J Bone Joint Surg [Br] 1985;67-B:78590.

6. Spirt AA, Assal M, Hansen ST. Complications and failure after total ankle arthroplasty. J Bone Joint Surg [Am] 2004;86-A:1172-8.

7. Groth HE, Fitch HF. Salvage procedures for complications of total ankle arthroplasty. Clin Orthop 1987;224:244-50.

8. Chiunard E, Peterson RE. Distraction-compression bone graft arthrodesis of the ankle: a method especially applicable to children. J Bone Joint Surg [Am] 1963;45A:481-90.

9. Campbell CJ, Rinehart WT, Kalenak A. Arthrodesis of the ankle: deep autogenous inlay grafts with maximum cancellous-bone apposition. J Bone Joint Surg [Am] 1974;56-A:63-70
10. Buck P, Morrey BF, Chao EYS. The optimum position of arthrodesis of the ankle: gait analysis study of the knee and ankle. J Bone Joint Surg [Am]1987;69-A:1052-62.

11. Kitaoka HB, Alexander IJ, Adelaar RS, et al. Clinical rating system for anklehindfoot, midfoot, hallux, and lesser toes. Foot Ankle Int 1994;15:349-53.

12. Gabrion $\mathbf{A}$, Jarde $\mathbf{0}$, Havet $\mathbf{E}$, et al. Ankle arthrodesis after failure or a total ankle prosthesis: 8 cases. Rev Chir Orthop Reparatrice Appar Mot 2004;90:353-9 (in French).

13. Hopgood P, Kumar R, Wood PLR. Ankle arthrodesis for failed total ankle replacement. J Bone Joint Surg [Br] 2006;88-B:1032-8.

14. Kontis R, Pasapula C, Anwar F, Cooke PH, Sharp RJ. The management of failed ankle replacement. J Bone Joint Surg [Br] 2006;88-B:1039-47.

15. Carlsson AS, Montgomery F, Besjakov J. Arthrodesis of the ankle secondary to replacement. Foot Ankle Int 1998;19:240-5.

16. Anderson T, Rydholm U, Besjakov J, Montgomery F, Carlsson A Tibiotalocalcaneal fusion using retrograde intramedullary nails as salvage procedure for failed total ankle prosthesis in rheumatoid arthritis: a report of sixteen cases. Foot Ankle Surg 2005;11:43-7.

17. Stauffer RN. Salvage of painful total ankle arthroplasty. Clin Orthop 1982;170:184-8.

18. Kile TA, Donnelly RE, Gehrke JC, Werner ME, Johnson KA. Tibiotalocalcaneal arthrodesis with an intramedullary device. Foot Ankle Int 1994;15:669-73.

19. Makwana NK, Morrison P, Jones CB, Kirkup J. Salvage operations after total ankle replacement. The Foot 1995;5:180-4

20. Kitaoka HB, Romness DW. Arthrodesis for failed ankle arthroplasty. J Arthroplasty 1992:7:277-84

21. Thomas R, Daniels TR, Parker K. Gait analysis and functional outcomes following ankle arthrodesis for isolated ankle arthritis. J Bone Joint Surg [Am] 2006;88-A:526-

22. Button G, Pinney S. A meta-analysis of outcome rating scales in foot and ankle surgery: is there a valid, reliable, and responsive system? Foot Ankle Int 2004;25:521-25.

23. Bruggeman NB, Kitaoka HB. Arthrodesis after failed total ankle arthroplasty. Techniques in Foot and Ankle Surg 2002;1:60-8.

24. Greisberg J, Assal M, Flueckiger G, Hansen ST. Takedown of ankle fusion and conversion to total ankle replacement. Clin Orthop 2004;424:80-8. 